\title{
Analysis of insoluble proteins
}

\author{
Sarah Trimpin ${ }^{1}$ and Bill Brizzard ${ }^{2}$ \\ ${ }^{1}$ Department of Chemistry, Wayne State University, Department of Chemistry, Detroit, Michigan, USA, and \\ ${ }^{2}$ Indiana University Research and Technology Corporation, Bloomington, Indiana, USA
}

BioTechniques 46:Special Online Content (April 2009 Special issue) doi 10.2144/000113135

Keywords: fusion tag; recombinant protein; solvent-free mass spectrometry; MALDI; IMS

The analysis of insoluble proteins represents a major technical challenge for the field of proteomics. For example, membrane proteins are often insoluble in common solvents and represent $20-30 \%$ of the proteins encoded by the human genome. Chemical analysis on an individual basis is often required and is laborious and time consuming. This review presents an overview of methods for purification of expressed proteins using fusion tags as well as methods for analysis of insoluble proteins by mass spectrometry with a goal of achieving high-throughput analysis.

\section{Introduction}

The human genome is estimated to encode 28,913 distinct proteins (1). The research effort to identify, characterize, and analyze the proteins encoded by the human genome, as well as that of other organisms, represents the field of proteomics. The complexity of this task is increased by the need to study proteins at the level of cells and tissues, as well as at the organismal level. A variety of techniques are employed in this effort, including both computational methods and biochemical methods. There have been many technical advances in the field such as two-dimensional (2-D) gels, mass spectrometry (MS), and robotics. However, a significant technical barrier remains in that many proteins are frequently insoluble in common solvents. For example, some proteins such as membrane proteins can be insoluble because they are hydrophobic. Moreover, misfolded proteins have exposed hydrophobic regions and can form insoluble aggregates. Many recombinant proteins, when overexpressed in a heterologous host, become insoluble because of misfolding.

So why study insoluble proteins? Misfolded proteins can cause diseases such as the amyloid- $\beta$ plaques in Alzheimer's disease (2). Moreover, many proteins such as membrane proteins, for example, are poorly soluble or entirely insoluble if extracted from their native environment. It has been estimated that $20-30 \%$ of the human genome encodes membrane proteins $(3,4)$ but less than $1 \%$ of the proteins of known structure are membrane proteins (5). Membrane proteins include receptor proteins and ion channels which represent important potential targets for therapeutics. An example from the field of neurobiology is the synapse, which consists of more than 2000 proteins (6). At even higher complexity are tissue samples, which contain a huge array of compounds, many of which are insoluble. These samples must retain their 3-D structure during analysis because of the importance of elucidating the location of particular molecular species within small areas of tissue (an example are specific brain centers, which can be crucial for assessing biological function).

The experimental study of insoluble proteins presents a challenge to the field of proteomics. While a number of powerful techniques have been developed for protein profiling, it is still necessary to purify individual proteins. Moreover, given the unique properties of each protein, it is still necessary to work out individual conditions on a case-by-case basis. For example, a thorough understanding of an individual protein requires the determination of its crystal structure, which often requires expression of recombinant proteins in order to obtain a sufficient quantity of purified protein for crystallization. Similarly, milligram quantities of a purified protein are required to generate antibodies for use in subsequent analyses such as antibody arrays; these quantities are also dependent upon recombinant protein expression and purification. This review presents an overview of available methods useful in the study of insoluble cellular proteins, as well as in the expression and purification of insoluble recombinant proteins.

\section{Expression and purification of recombinant proteins}

Just as the best method for protein purification must be determined on an individual basis, the best method for expression and purification of recombinant proteins must also be determined on an individual basis.
Expression systems have been created for numerous hosts including $E$. coli, yeast, insect, and mammalian cells. However, it is often not clear which host will produce a sufficient yield of expressed, soluble protein. In many cases it is necessary to try various hosts and expression systems. This task has been greatly facilitated by the introduction of recombination-based cloning systems which are available for multiple host cell types (7). Once a gene encoding a protein of interest has been cloned into the first vector, the gene may then be transferred by recombination into multiple additional vectors without the need for recloning. Although each expression host offers particular advantages, the first choice for simplicity and yield is E. coli. However, when heterologous proteins are expressed in E. coli or other expression hosts, they often form insoluble inclusion bodies. Proteins can be purified from inclusion bodies, but refolding the protein is required and proteins have variable refolding properties (8).

A valuable tool for recombinant protein expression and purification is the use of epitope tagging in which a polypeptide tag is fused to the target protein in a suitable expression vector. Again, the process is facilitated through the use of recombinationbased cloning vectors as numerous choices of vectors and epitope tags are available (9). The expressed protein may then be purified using a ligand with affinity for the epitope tag. One of the first epitope tags to prove useful for purifying recombinant proteins was the His tag (10). His-tagged proteins can be purified by immobilized metal affinity chromatography and the method is compatible with chaotropic agents (urea or guanidine hydrochloride) so that proteins from inclusion bodies can be solubilized and bound to the affinity matrix (11). Furthermore, 
if the fusion protein contains the recognition sequence for a specific protease, the affinity tag can be removed while the protein is immobilized on the affinity column.

In addition to their utility as tags for affinity purification, some larger fusion tags, when fused to an insoluble protein, can render the fusion protein soluble. The first fusion tag to be developed specifically for this purpose was $E$. coli thioredoxin (12). Subsequently, a large fusion tag of 495 amino acids was created from the $E$. coli nus $A$ (nusA) gene following a solubility analysis of the $E$. coli genome (13). Other fusion tags reported to enhance solubility are glutathione-S-transferase (GST) and maltose binding protein (MBP). Korf et al. compared the nus $A$, His, MBP, and GST fusion tags for yield of soluble expressed fusion protein and found that MBP and $n u s A$ fusions were more likely to produce soluble fusion proteins than His and GST (9).

Another benefit of fusion tags is that their addition may make protein purification amenable to high-throughput techniques. Many commercial vendors have developed reagents, kits, and tools for automated purification of tagged proteins, including His-tagged proteins. For example, SigmaAldrich (St. Louis, MO, USA) sells 96-well iLAP Plates pre-coated with cell lysis reagents and immobilized metal affinity chromatography (IMAC) resin. Similarly, Pall Corporation (East Hills, NY, USA) offers multiwell filter plates (AcroPrep 96 Filter Plate) for highthroughput purification of tagged proteins and Novagen (Gibbstown, NJ, USA) offers kits (RoboPop) for automated solubility screening of tagged proteins. Moreover, Promega Corporation (Madison, WI, USA) has developed a magnetic purification method (MagneHis) for purification of His-tagged proteins that is adapted to several automated workstations. GE Healthcare (Piscataway, NJ, USA) has an automated chromatography system (AKTAxpress) that is compatible with both His- and GST-tagged proteins.

In addition to the use of fusion tags, other techniques may be employed for analysis of insoluble proteins. Klammt et al. (14) successfully expressed $E$. coli integral membrane proteins in an $E$. coli cell-free system and solubilized the expressed proteins with detergent micelles. Roche Applied Science (Indianapolis, IN, USA) offers the Rapid Translation System (RTS), a commercial product for high-throughput cell-free transcription and translation, and recently, the development of a microfluidic device for in vitro transcription and translation has been reported (15). Another technique that has been successful in some instances is co-expression of chaperones. Sorensen and
Mortensen have reviewed expression strategies in E. coli (16).

\section{Expression profiling and \\ mass spectrometry}

Proteomic analysis aims at profiling the expression of proteins in a particular biological compartment (preferably an easily accessible body fluid) by a comparative analysis of different samples to identify differentially expressed proteins among healthy, diseased, and/or drug-treated populations. The traditional method for proteomic profiling has been 2-D gel electrophoresis. However, the technique has limitations for the analysis of insoluble proteins in that hydrophobic proteins are not soluble in the first-dimension isoelectric focusing buffer (5). An alternative to first-dimension isoelectric focusing is blue native gel electrophoresis in which protein complexes are resolved in native form in the first dimension prior to denaturing SDS-PAGE in the second dimension (17). Proteins separated by 2-D gel electrophoresis can then be identified by MS. Gel-based MS approaches are more powerful due to unparalleled resolving power of the 2-D gel along with the ease of comparison of visualized protein spots. These protein spots are subjected to tryptic digestion, eluted from the gel, and analyzed by MS, MS/MS, and respective database searches. But this approach can be time-consuming and cumbersome for protein analysis with increasing solubility restrictions and/or modifications (18-23).

Shotgun proteomics, a solely MS-based approach, is significantly faster $(24,25)$. In MS-based proteomics, two general approaches are used. In the bottom-up approach, proteins of interest are treated with a protease (preferentially trypsin because of its specific cleavage sites at arginine and lysine residues) to ideally produce a complete digestion of the protein. The resulting peptide mixture is analyzed by MS and individual signals are mass selected for fragment ion analysis. Verification of primary sequence and determination of possible amino acid variations or modified sites is supported by powerful databases and search engines (24-26). The mass information for each peptide is then combined to characterize the protein. Quantitative information generally relies on chemical labeling (27), but label-free approaches have been explored (28).

In the top-down approach, proteins of interest are directly subjected to MS to obtain intact molecular weight information. In the same experiment, by a simple switch of instrumental conditions, fragmentation can be induced using electron capture dissociation (ECD) (29) or electron transfer disso- ciation (ETD) (30). This then produces the sequence information and respective modifications data directly from the protein. Entire sequence information is often problematic to achieve because fragmentation preferentially occurs at the $\mathrm{C}$ - and $\mathrm{N}$-termini of a protein. Top-down is fast and promising, though presently, instrumentation is expensive and the information describing the protein is often considerably more limited than with the bottom-up approach. Nevertheless, this is an area which will no doubt improve, making this the standard method in the future.

In addition to its usefulness for the analysis of complex mixtures, MS has the power to detect solubilized materials present in attomole amounts $(11,32)$. However, for many types of compounds (e.g., peptides), this is possible only when the higher-abundance compounds in complex mixtures have been removed. As a consequence, the primary focus of MS-based materials analysis, in particular shotgun approaches, has shifted toward powerful technological marriages. For example, condensed-phase chromatographic methods such as liquid chromatography (LC) and capillary electrophoresis (CE) have become increasingly important as protein and peptide separation technologies for proteomic analysis of plasma and other complex biological samples. However, multidimensional separation techniques are only applicable for materials that can be solubilized in solvents suitable for the analysis. Unfortunately, multidimensional separations dramatically increase the number of fractions produced with a concomitant increase in the analysis time $(33,34)$. An additional disadvantage of condensed phase chromatography methods is the limited reproducibility, particularly for those materials near the fraction boundaries. The eluting molecules at the boundaries are analyzed multiple times, increasing the amount of data acquired and stored without gaining additional information and while reducing the sample concentration. This causes a bottleneck in data acquisition, interpretation, and storage; and limits accurate quantitative materials measurements using these traditional separation technologies.

These advances in proteomics were only possible because of the introduction of electrospray ionization (ESI) (35) and matrix-assisted laser desorption/ionization (MALDI) $(36,37)$ for providing high MS sensitivity for protein characterization. Both ionization methods are soft in that primarily molecular ions are formed from proteins of any size. More recently, MALDI MS has shown great promise as a mass-specific means of tissue imaging (38-43) offering to further chemical analysis in such diverse areas as drug-dosing studies and cancer boundary detection $(38,44,45)$. Perhaps the 
most rewarding advantage of MALDI is its capability of observing singly charged ions over a wide mass range (less than $100 \mathrm{Da}$ to over 1,000,000), which contributes to its ability to analyze small and large constituents of tissue materials. Consequently, current imaging applications aim at examining changes in the proteome to attain a better understanding of molecular diseases, such as Parkinson's $(40,46)$ and cancer $(47,48)$. Thus, analysis of hundreds of proteins directly from tissue slices along with their spatial distributions is possible (47).

Major challenges associated with this imaging method include the need to analyze the tissue under vacuum conditions, interference and suppression caused by the multitude of compounds in these complex samples, degradation of the spatial resolution upon deposition of the MALDI matrix, insufficient detection sensitivity, and limited dynamic range of a purely MS-based approach. Quantitation is problematic because of the poorly understood and controllable nature of ablated and ionized molecules from a given sample spot. Additionally, the matrix background can interfere in the analysis of small molecules. In spite of the superb inherent sensitivity of MALDI MS (31), the extreme complexity of the tissue composition and the limited dynamic range of the detector relative to the concentration range of the most abundant to least abundant proteins makes tissue imaging challenging. Additional problems arise from factors such as ion suppression. Furthermore, with a MS approach, isomeric compounds are not distinguished, even using high-resolution Fourier transform ion cyclotron resonance (FT-ICR) MS instrumentation (49,50), a drawback that is especially problematic in studying modified peptides carrying the same post translational modifications, but on different amino acids $(38,51,52)$.

\section{Solvent-free sample prepar- ation and ionization: a logical method for insoluble proteins}

Many biological materials either cannot or should not undergo condensed phase separation analysis. A promising avenue for analysis of poorly soluble biological materials is an approach for chemical analyses that avoids the use of solvents to the greatest extent possible $(53,54)$. This new area of research has yielded novel methods in sample preparation (55-57), ionization (58-60) and separation (61-64) in conjunction with MS analysis. Solventbased MALDI applications often involve considerable effort to produce the homogenous coverage necessary for quantitative or even reproducible qualitative results. For these and related reasons (e.g., migration and segregation upon the use of solvent), applications requiring throughput and quantitation can be extremely limited with conventional solvent-based MALDI methods $(34,65,66)$. Consequently, solvent-free methods are currently finding use in applications (67-72).

Solvent-free MALDI analysis on cytochrome $\mathrm{c}$ showed that very homogeneous coverage can be obtained in a straightforward manner. The resultant homogenous sample consequently produces ions from literally every laser spot, using less laser power because of the absence of variability in crystal sizes (73), thus effectively reducing undesired analyte fragmentation and chemical background (matrix signals) (74). Additionally, the loss of sample during protein downstream handling can be as large as 50\% (75-77). This limitation is mostly avoided in the solvent-free MALDI method because the sample is effectively recovered from the wall of the vial during the required step of mixing the analyte and MALDI matrix using beads mechanically (58).

Another example of the solventfree MALDI method is the analysis of amyloid peptides. The amyloid peptide $(1-42)$ is pivotal in the pathogeneis of Alzheimer's disease, promoting oxidative stress and converting to insoluble neurotoxic $\beta$-amyloid fibril forms (78-83). Besides changes in protein modifications related to acetylations and phosphorylations relevant to Alzheimer's disease (84), abundant evidence suggests crucial involvement of His-6, His-13, His-14 and Met-35. Oxidation of Met-35 is also discussed as a cause of the onset of misfolding the amlyloid precursor protein (APP) and Alzheimer's disease. Recent work shows that artifacts occur (oxidation of tryptophan and methionine residues) that are related to solvent-based MS sample preparation $(85,86)$. These artifacts are produced in the same time period in which the solutions of sample and matrix are combined; the reaction stops when the MALDI sample is dry. Thus, solvent-based MS, in applications related to understanding oxidative stress, is invalid at the moment. However, hydrophobic components of amyloid peptides showed that solvent-free MALDI analyses overcome these oxidation artifacts, as well as solubility issues, without use of MS incompatible detergents (58). Ionization suppression of hydrophobic peptides along with shot-to-shot irreproducibility are also greatly reduced improving quantitative aspects of analysis $(58,73)$. The tryptic digested amyloid peptide (1-42) gave $100 \%$ sequence coverage with a solvent-free approach, whereas solvent-based MALDI did not detect the hydrophobic peptides due to solubility and ionization issues (58). Similar improvements were found for the analysis of bacteriorhodopsin, a membrane protein (59).

Solvent-free MALDI methods utilizing respective sample holders (e.g., microtitre plates) with simultaneous preparation, homogenization, and deposition directly onto the MALDI plate (87-89) have enhanced the prospect of highthroughput analysis. Current limitations of the solvent-free MALDI method for protein/peptide analysis are a higher material requirement relative to solventbased methods and a greater tendency for metal adduction which may increase the analysis time. It is, however, the ability to attach a metal cation $\left(\mathrm{Na}^{+}\right)$that makes the analysis of hydrophobic peptides reliable using solvent-free MALDI analysis (58). Hydrophobic peptides are frequently not sufficiently basic to be protonated. Future research will address these issues, as well as others, perhaps enabling high-throughput analysis of insoluble proteins.

\section{Solvent-free gas phase sepa- ration: IMS, a natural part- ner to solvent-free ionization}

Solvent-free sample preparation and ionization are only part of what is required for total solvent-free analysis by mass spectrometry of complex systems. Separation methods are critical in reducing complexity, but condensed phase separations are, by definition, problematic with poorly soluble and insoluble materials in addition to sample loss and oxidation issues. Clemmer and colleagues (61-63, 90-92) as well as others (93) developed ion mobility (IMS) interfaced with MS as a powerful gas phase separation technology, enabling the analysis of many complex materials including those with isomeric compositions (62-64). IMS-MS provides a means of solvent-free separation and analysis.

An example of the power of IMS-MS was demonstrated by online coupling of liquid phase separation with ESI-IMSMS for the analysis of fractions of plasma proteins (61) that were similar to those created for interlaboratory analysis efforts coordinated through the Human Proteome Organization (HUPO) Plasma Proteome Project (94). The HUPO endeavor - the work of eighteen laboratories around the world-resulted in more 
than 3020 high-confidence protein identifications by incorporating multidimensional condensed-phase separation and MS technologies [e.g., SCX-reverse phase LC (RPLC)-MS] (94). In comparison, the finding using SCX-LC-IMS-MS from the plasma of five healthy people resulted in 2928 high-confidence assignments (61). Hence, the number of plasma proteins identified by a single laboratory with only a few samples equaled that identified by a large team effort, an accomplishment made possible by the addition of IMS-MS. More recently, attomole sensitivities were achieved using ESI-IMS-MS (95). In the future, the combination of solvent-free MALDI sample preparation (53-60,73,74,87-89) with solvent-free separation $(61,62,64)$ and MS detection methods will provide a powerful total solvent-free MS approach for the analysis of solubility-restricted materials.

\section{Methods that are needed in the future}

The insoluble portion of the proteome is vast and mostly unexplored. Significant advances in analytical methodologies will be required to fully explore this landscape. The prospects are bright, however, considering advances made in the past 25 years for soluble proteins. Without advances in characterization of the insoluble components of living organisms, our knowledge of biological processes is compromised. Perhaps the most daunting of all challenges is the determination not just of structurefunction relationships involving proteinprotein, protein-drug, and other cell signaling molecules, but determining how all the various cellular and intracellular systems interact. Certainly, this will require the characterization of unadulterated tissue material, and superior technology with increased sensitivity, dynamic range, spatial resolution, and high-throughput capability. A macroscopic view of the molecular makeup including the 3-D arrangements of components can only be achieved by powerful technological marriages within MS and beyond. Some of these may include top-down total solventfree proteomics analysis requiring enhancements in efficient fragmentation (ECD, ETD) of unadulterated proteins directly from the tissue materials, ideally providing (nearly) complete sequence coverage and thus unraveling all protein modifications present in a single experiment. Finally, finding faster and more efficient ways to store and process the vast amounts of data produced by these analytical methods remains a significant challenge.

\section{Acknowledgments}

The authors thank James Drummond and Charles McEwen for advice and comments on the manuscript.

The authors declare no competing interests.

\section{References}

1.Muller, A., R.M. MacCallum, and M.J.E. Sternberg. 2002. Structural characterization of the human proteome. Genome Research 12:1625-1641.

2.Bucciantini, M.,E. Giannoni, F. Chiti, F. Baroni, L. Formigli, J. Zurdo, N. Taddie, G. Ramponi, et al. 2002. Inherent toxicity of aggregates implies a common mechanism for protein misfolding diseases. Nature 416:507511.

3. Wallin, E. and G. Von Heijne. 1998. Genomewide analysis of integral membrane proteins from eubacterial, archaean, and eukaryotic organisms. Protein Sci. 7:1029-1038.

4.Stevens, T.J. and I.T. Arkin. 2000. Do more complex organisms have a greater proportion of membrane proteins in their genomes? Proteins 39:417-420.

5. Wu, C.C. and J.R. Yates, III. 2003. The application of mass spectrometry to membrane proteomics. Nature Biotechnology 21:262267.

6. Li, K.W. and A.B. Smit. 2007. Proteomics of brain synapses and molecular dissection of synaptic subdomains. Proteomics Clin. Appl. I:1476-1484.

7. Hartley, J.L., G.F. Temple, and M.A. Brasch. 2000. DNA cloning using invitro site-specific recombination. Genome Research 10:17881795.

8. Padan, E., C. Hunte, and H. Reilander. 2003. Production and purification of recombinant membrane proteins, p. 55-83. In C. Hunte, G. von Jagow, and H. Schagger (Eds.), Membrane Protein Purification and Crystalization A Practical Guide. Academic Press. San Diego.

9. Korf, U., T. Kohl, H. Van der Zandt, R. Zahn, S. Schleeger, B. Ueberle, S. Wandschneider, S. Bechtel, et al. 2005. Large-scale protein expression for proteome research. Proteomics 5:3571-3580.

10. Hochuli, E., W. Bannarth, H. Dobeli, R. Gentz, and D. Stuber. 1988. Genetic approach to facilitate purification of recombinant proteins with a novel metal chelate adsorbent. Biol./Technology 6:1321-1325.

11.Holzinger, A., K.S. Phillips, and T.E. Weaver. 1996. Single-step purification/ solubilization of recombinant proteins: application to surfactant protein $\mathrm{B}$. BioTechniques 20:804-806.

12.LaVallie, E.R., E.A. DiBlasio, S. Kovacic, K.L. Grant, P.F. Schendel, and J.M. McCoy. 1993. A thioredoxin gene fusion expression system that circumvents inclusion body formation in the E. coli cytoplasm. Biol./ Technology 11:187-93.

13. Harrison, R. G. 2000. Expression of soluble heterologous proteins via fusion with NusA protein. Innovations 11:4-7.

14. Klammt, C., F. Lohr, B. Schafer, W. Haase, V. Dotsch, H. Ruterjans, C. Glaubitz, and F. Bernhard. 2004. High level cell-free expression and specific labeling of integral membrane proteins. Eur. J. Biochem. 271:568580 .
15. Mei, Q., C.K. Fredrickson, A. Simon, R. Khnouf, and Z. H. Fan. 2007. Cell free protein synthesis in microfluidic array devices. Biotechnol. Prog. 23:1305-1311.

16. Sorensen, H.P. and K.K. Mortensen. 2005. Advanced genetic strategies for recombinant protein expression in Escherichia coli. J. Biotechnology 115:113-128.

17. Brookes, P.S., A. Pinner, A. Ramachandran, L. Coward, S. Barnes, H. Kim, and V.M. DarleyUsmar. 2002. High throughput two-dimensional blue-native electrophoresis: A tool for functional proteomics of mitochondria and signaling complexes. Proteomics 2:969-977.

18.Zischa, H., C.J. Gloeckner, C. Klein, S. Willmann, M. Swiatek-de Lange, and M. Ueffing, 2004. Improved mass spectrometric identification of gel-separated hydrophobic membrane proteins after sodium dodecyl sulfate removal by ion-pair extraction. Proteomics 4:3776-3782.

19. Klein, C., C. Garcia-Rizo, B. Bisle, B. Scheffer, H.Zischka, F. Pfeiffer, F. Siedler, and D. Oesterhelt. 2005. The membrane proteome of Halobacterium salinarum. Proteomics 5:180-197.

20. Bisle, B., A. Schmidt, B. Scheibe, C. Klein, A. Tebbe, J. Kellermann, F. Siedler, F. Pfeiffer, F. Lottspeich, D. Oesterhelt. 2006. Quantitative profiling of the membrane proteome in a halophilic archaeon. Mol. Cell. Proteomics 5:1543-1558.

21. Poetsch, A., D. Schlüsener, C. Florizone, L. Eltis, C. Menzel, M. Rögner, K. Steinert, and U. Roth. 2008. Improved identification of membrane proteins by MALDI-TOF MS/MS using vacuum sublimated matrix spots on an ultraphobic chip surface. J. Biomol. Tech. 19:129-138.

22. Weiner, J.H. and L. Li. 2008. Proteome of the Escherichia coli envelope and technological challenges in membrane proteome analysis. Biochim. Biophys. Acta 1778:16981713.

23.Pan, Y., B.B. Stocks, L. Brown, and L. Konermann. 2009. Structural characterization of an integral membrane protein in its natural lipid environment by oxidative methionine labeling and mass spectrometry. Anal. Chem. 81:28-35.

24. Washburn, M.P., D. Wolters, and J.R. Yates, III. 2001. Large-scale analysis of the yeast proteome by multidimensional protein identification technology. Nat. Biotechnol. 19:242-247.

25. Lin D., A.J. Alpert, and J.R. Yates, III. 2001. Multidimensional protein identification technology as an effective tool for proteomics. Am. Genomic/Proteomic Technol. 1: 38-46.

26.Larsen, M.R., M.B. Trelle, T.E. Thingholm, and O.N. Jensen. 2006. Analysis of posttranslational modifications of proteins by tandem mass spectrometry. Biotechniques. 40:790-798.

27. Turecek, F. 2001. Mass spectrometry in coupling with affinity capture-release and isotope-coded affinity tags for Quantitative protein analysis. J. Mass Spectrom. 37:1-14

28. Ono, M., M. Shitashige, K. Honda, T. Isobe, H. Kuwabara, H. Matsuzuki, $S$. Hirohashi, T. Yamada. 2006. Label-free quantitative proteomics using large peptide data sets generated by nanoflow liquid chromatography and mass spectrometry. Mol Cell Proteomics. 5:1338-47.

29 Zubarev, R., N.L. Kelleher, and F.W. McLafferty. 1998. Electron capture dissociation of 
multiply charged protein cations. A nonergodic process. J. Am. Chem. Soc. 120:32653266.

30.Syka, J.E.P., J.J.Coons, M.J. Schroeder, J. Shabanowitz, and D.F. Hunt. 2004. Peptide and protein sequence analysis by electron transfer dissociation mass spectrometry. Proc. Natl. Acad. Sci. 101:9528-9533.

31.Smalley, D.M. and K. Ley. 2008. Plasma-derived microparticles for biomarker discovery. Clin Lab. 54:67-79.

32. Hachey, D.L. and P. Chaurand. 2004. Proteomics in reproductive medicine: the technology for separation and identification of proteins. J. Reprod. Immunol. 63:61-73.

33. Lohaus, C., A. Nolte, M. Blüggel, C. Scheer, J. Klose, J. Gobom, A. Schüler, T. Wiebringhaus, H.E. Meyer, and K. Marcus. 2007. Multidimensional chromatography: a powerful tool for the analysis of membrane proteins in mouse brain. J. Proteome Res. 6:105-113.

34.McComb, M.E., D.H. Perlman, H. Huang, and C.E. Costello. 2007. Evaluation of an on-target sample preparation system for matrix-assisted laser desorption/ ionization time-of-flight mass spectrometry in conjunction with normal-flow peptide high-performance liquid chromatography for peptide mass fingerprint analyses. Rapid Commun. Mass Spectrom. 21:44-58.

35. Yamashita, M. and J.B. Fenn. 1984. Electrospray oon source. Another viariation on the free-jet theme. J. Phys. Chem. 88:46714675.

36. Tanaka, K., H. Waki, Y. Ido, S. Akita, Y. Yoshida, T. Yoshida, 1988. Protein and polymer analysis up to $\mathrm{m} / \mathrm{z} 100,000$ by laser ionization time-of-flight mass spectrometry. Rapid Commun. Mass Spectrom. 2:151-153.

37. Karas, M. and F. Hillenkamp. 1988, Laser desprption ionization of proteins with molecular masses exceeding 10,000 Daltons. Anal. Chem. 60:2299-2301.

38.Li, L., R.W. Garden, and J.V. Sweedler. 2000. Single-cell MALDI: a new tool for direct peptide profiling. Trends Biotechnol. 18:151160.

39.Stoeckli, M., P. Chaurand, D.E. Hallahan, and R.M. Caprioli. 2001. Imaging mass spectrometry: A new technology for the analysis of protein expression in mammalian tissues. Nature Med. 7:493-496.

40.Rohner, T.C., D. Staab, and M. Stoeckli, 2004. MALDI mass spectrometric imaging biological tissue sections. Mech. Ageing Dev. 126:177-185.

41. McDonnell, L.A. and R.M. Heeren. 2007. Imaging mass spectrometry. Mass Spectrom Rev. 26:606-643.

42 Cornett, D. S., M. L. Reyzer, P. Chaurand, and R. M. Caprioli. 2007. MALDI imaging mass spectrometry: molecular snapshots of biochemical systems. Nature Methods 4:828833.

43. Fournier, I., M. Wisztorski, and M. Salzet. 2008. Tissue imaging using MALDI-MS: a new frontier of histopathology proteomics. Expert Review of Proteomics 5:413-424.

44.Khatib-Shahidi, S., M. Andersson, J. L. Herman, T. A. Gillespie, and R. M. Caprioli. 2006. Direct molecular analysis of whole-body animal tissue sections by imaging MALDI mass spectrometry. Anal. Chem. 78:6448-6456.
45. Chaurand, P., D. S. Cornett, and R. M. Caprioli. 2006. Molecular imaging of thin mammalian tissue sections by mass spectrometry. Curr. Opin.Biotechnol. 17:431436.

46.Pierson, J., J.L. Norris, H-R. Aerni, P. Svenningsson, R.M. Caprioli, and P.E. Andren. 2004. Molecular profiling of experimental Parkinson's disease: direct analysis of peptides and proteins on brain tissue sections by MALDI mass spectrometry. J. Proteome Res. 3:289-295.

47. Chaurand, P., S.A. Schwartz, and R.M. Caprioli. 2004. Assessing protein patterns in disease using imaging mass spectrometry. J. Proteome Res. 3:245-252.

48. Chaurand, P., S.A. Schwartz, and R.M. Caprioli. 2004. Profiling and imaging proteins in tissue sections by MS. Anal. Chem. $76: 86 \mathrm{~A}-93 \mathrm{~A}$.

49.He, F., M.R., Emmett, K. Håkansson, C.L. Hendrickson, and A.G. Marshall. 2004. Theoretical and experimental prospects for protein identification based solely on accurate mass measurement. J. Proteome Res. 3:61-67.

50.Fu, M., P., Duan, S., Li, S.C., Habicht, D.S., Pinkston, N.R., Vinueza, and H.I. Kenttämaa. 2008. Regioselective ion-molecule reactions for the mass spectrometric differentiation of protonated isomeric aromatic diamines. Analyst. 133:452-454.

51. Trimpin, S., A.E. Mixon, M. Stapels, M.-Y. Kim, P.S. Spencer, and M.L. Deinzer, 2004. Identification of endogenous phosphorylation sites of bovine medium and low molecular weight neurofilament proteins by tandem mass spectrometry. Biochemistry 43:2091-2105.

52.Zhang, Y., E. P. Go, H. Jiang, and H. Desaire. 2005. A novel mass spectrometric method to distinguish isobaric monosaccharides that are phosphorylated or sulfated using ion-pairing reagents. J. Am. Soc. Mass Spectrom. 16:1827-1839.

53. Trimpin, S. and M.L. Deinzer. 2005. Solvent-free mass spectrometry for hydrophobic peptide sequence analysis and protein conformation studies. BioTechniques. 39:799805.

54.Trimpin, S. 2006. Solvent-free matrix-assisted laser desorption ionization, p. 683-689. In M.L. Gross and R.M. Caprioli (Eds.) Encyclopedia of Mass Spectrometry: Molecular Ionization, Vol. 6. Elsevier, Amsterdam.

55. Trimpin, S., A. Rouhanipour, R. Az, H.J. Räder, and K. Müllen. 2001. New aspects in matrix-assisted laser desorption/ ionization time-of-flight mass spectrometry: a universal solvent-free sample preparation. Rapid Commun. Mass Spectrom. 15:13641373.

56. Trimpin, S. and M.L Deinzer. 2005. Solvent-free MALDI-MS for the analysis of biological samples via a mini-ball mill approach. J. Am. Soc. Mass Spectrom. 16:542547.

57. Trimpin, S. and C.N. McEwen. 2007. A Multi-Sample on-target homogenization/ transfer method for solvent-free MALDI-MS analysis of synthetic polymers. J. Am. Soc. Mass Spectrom. 18:377-381.

58. Trimpin, S. and M.L Deinzer. 2007. Solvent-free MALDI-MS for the analysis of $\beta$-amyloid peptides via the mini-ball mill approach: qualitative and quantitative improvements. J. Am. Soc. Mass Spectrom. 18:1533-1543.

59. Trimpin, S. and M.L Deinzer. 2007. Solvent-free MALDI-MS for the analysis of a membrane protein via the mini-ball mill approach: a case study of bacteriorhodopsin. Anal. Chem. 79:71-78.

60.Trimpin, S., D.E. Clemmer, and C.N. McEwen. 2007. Charge-remote fragmentation of lithiated fatty acids on a TOF-TOF instrument using matrix-ionization. J. Am. Soc. Mass Spectrom. 18:1967-1972.

61. Liu, X., S.J. Valentine, M.D. Plasencia, S. Trimpin, S. Naylor, and D.E. Clemmer. 2007. Mapping the human plasma proteome by SCX-LC-IMS-MS. J. Am. Soc. Mass Spectrom. 18:1249-1264.

62. Trimpin, S. and D.E. Clemmer. 2008 Ion mobility spectrometry/mass spectrometry/ mass spectrometry for assessing the molecular compositions of complex polymeric systems. Anal. Chem. 80:9073-9083.

63. Plasencia, M.D., D., Isailovic, S.I., Merenbloom, Y., Mechref, and D.E. Clemmer. 2008. Resolving and assigning N-linked glycan structural isomers from ovalbumin by IMS-MS. J. Am. Soc. Mass Spectrom. 19:17061715.

64.Trimpin, S., B. Tan, B.C. Bohrer, D.K O'Dell, S.I. Merenbloom, M.X. Pazos, D.E. Clemmer, and J.M. Walker. 2009. Profiling of Phospholipids and Related Lipid Structures using Multidimensional Ion Mobility Spectrometry-Mass Spectrometry. Int. J. Mass Spectrom. (In press.)

65. Bouschen, W. and B. Spengler. 2007. Artifacts of MALDI sample preparation investigated by high-resolution scanning microprobe matrix-assisted laser desorption/ionization (SMALDI) imaging mass spectrometry. Int. J. Mass Spectrom. 266:129-137.

66. Timms, J.F. and R. Cramer. 2008 Difference gel electrophoresis. Proteomics. 8:4886-4897.

67. Soltzberg, L.J., J.D. Slinker, S. FloresTorres, D.A. Bernards, G.G. Malliaras, H.D. Abruña, J.S. Kim, R.H. Friend, et al. 2006. Identification of a quenching species in ruthenium tris-bipyridine electroluminescent devices. J. Am. Chem. Soc. 128:7761-7764.

68.Eelman M.D., J.M. Blacquiere, M.M. Moriarty, and D.E. Fogg. 2008. Shining new light on an old problem: retooling MALDI mass spectrometry for organotransition-metal catalysis. Angew. Chem. Int. Ed. Engl. 47:303306.

69. Hankin, J.A., R.M. Barkley, and R.C. Murphy. 2007. Sublimation as a method of matrix application for mass spectrometric imaging.J.Am. Soc. Mass Spectrom. 18:16461652

70.Puolitaival, S.M., K.E. Burnum, D.S. Cornett, and R.M. Caprioli. 2008. Solventfree matrix dry-coating for MALDI imaging of phospholipids. J Am Soc Mass Spectrom. 19:882-886.

71.Hanton, S.D., T.M. McEvoy, and J.R. Stets. 2008. Imaging the morphology of solvent-free prepared MALDI samples. J. Am. Soc. Mass Spectrom. 19:874-881.

72.Soltzberg LJ, E. Hendrickson, A. McLaughlin, S. Newsky, C. Saikin, and M.Trieu. 2009. Metal contamination in matrix-assisted laser desorption/ionization samples prepared with the 'vortex' solventfree method. Rapid Commun. Mass Spectrom. 23:462-464. 
73. Trimpin, S., H.J. Räder, and K. Müllen. 2006. Experiments on theoretical principles of matrix-assisted laser desorption/ ionization mass spectrometry part I preorganization. Int. J. Mass Spectrom. 253:13-21.

74. Trimpin, S., S. Keune, H.J. Räder, and K. Müllen. 2006. Solvent-free MALDI-MS developmental improvements in the reliability and the potential of MALDI Analysis of synthetic polymers and giant organic molecules. J. Am. Soc. Mass Spectrom. 17:661671.

75. Speicher, K. D., O. Kolbas, S. Harper, and D. W. Speicher. 2000. Systematic analysis of peptide recoveries from in-gel digestions for protein identifications in proteome studies. J. Biomol. Tech. 11:74-86.

76. Stewart, I.I., T. Thomson, and D. Figeys. 2001. ${ }^{18} \mathrm{O}$ labeling: a tool for proteomics. Rapid Commun. Mass Spectrom. 15:2456-2465.

77. Nordhoff, E., H. Lehrach, and J. Gobom. 2007. Exploring the limits and losses in MALDI sample prperation of attomole amounts of peptides. Int. J. Mass Spectrom. 268:139-146.

78. Wunderlin, M., M. Schuhmacher, S. Trimpin, S. Bühler, A. Török, K. Soos, B. Penke, and M. Przybylski. 1999. Isolation and structural characterization of the amyloid precursor protein (APP) from human brain. Peptides-European Symposium, 25:330-331.

79. Mattson, M.P. 2004. Pathways towards and away from Alzheimer's disease. Nature 430:631-639.

80.Sayre, L.M., M.A. Smith, and G. Perry. 2001. Chemistry and biochemistry of oxidative stress in neurodegenerative disease. Curr. Med. Chem.8:721-738.

81. Bush, A.I., C.L. Masters, and R.E. Tanzi. 2003. Copper, beta-amyloid, and Alzheimer's disease: tapping a sensitive connection. Proc. Natl. Acad. Sci. USA 100:11193-11194.

82.Schoneich, C. and T.D. Williams. 2002. $\mathrm{Cu}$ (II)-catalyzed oxidation of $\beta$-amyloid peptide targets His13 and His14 over His6: detection of 2-Oxo-histidine by HPLC-MS/ MS. Chem. Res. Toxicol. 15:717-722.

83. Schoneich, C. 2002. Redox processes of methionine relevant to beta-amyloid oxidation and Alzheimer's disease. Arch. Biochem. Biophys. 397:370-376.

84.Deng, Y., B. Li, F. Liu, K. Iqbal, I. Grundke-Iqbal, R. Brandt, C.X. Gong. 2008. Regulation between O-GlcNAcylation and phosphorylation of neurofilament- $\mathrm{M}$ and their dysregulation in Alzheimer disease. FASEB J. 22:138-145.

85. Cohen, S.L. 2006. Ozone in ambient air as a source of adventitious oxidation: a mass spectrometric study. Anal. Chem. 78:4352-4362.

86. Froelich, J.M. and G.E. Reid. 2008. The origin and control of ex vivo oxidative peptide modifications prior to mass spectrometry analysis. Proteomics 8:1334-1345.

87. Trimpin, S. and C.N. McEwen. 2007. A multi-sample on-target homogenization/transfer method for solvent-free MALDI-MS analysis of synthetic polymers. J. Am. Soc. Mass Spectrom. 18:377-381.

88. Trimpin, S. S.M. Weidner, J. Falkenhagen, and C.N. McEwen. 2007. Fractionation and solvent-free maldi-ms analysis of polymers using liquid adsorption chromatography at critical conditions in combination with a novel multi-sample on-target homogenization/transfer sample preparation method. Anal. Chem. 79:75657570.

89. Trimpin, S., C.N. McEwen, H. Ji, and M.L. Deinzer. 2006. 144-Sample on-target parallel homogenization/transfer method for solvent-free MALDI-MS analysis of peptides and proteins. Mol. Cell Proteomics 5:S300.

90.Koeniger, S.L., S.I. Merenbloom, S.J. Valentine, M.F. Jarrold, H.R. Udseth, R.D. Smith, and D.E. Clemmer. 2006. An IMS-IMS analogue of MS-MS. Anal Chem. 78:41614174.

91. Merenbloom, S.I., S.L. Koeniger, S.J. Valentine, M.D. Plasencia, and D.E. Clemmer. 2006. IMS-IMS and IMS-IMSIMS/MS for separating peptide and protein fragment ions. Anal Chem. 78:2802-2809.

92.Bohrer, B.C., S.I. Merenbloom, S.L. Koeniger, A.E. Hildebrand, and D.E. Clemmer. 2008. Biomolecule Analysis by Ion Mobility. Annu. Rev. Anal. Chem. 1:293327.

93. Kanu, A.B., P. Dwivedi, M. Tam, L. Matz, and H.H. Hill Jr. 2008. Ion mobilitymass spectrometry. J. Mass Spectrom. 43:1-22.

94. Omenn, G.S., D.J. States, M. Adamski, T.W. Blackwell, R. Menon, H. Hermjakob, R. Apweiler, B.B. Haab, et al. 2005. Overview of the HUPO plasma proteome project: results from the pilot phase with 35 collaborating laboratories and multiple analytical groups, generating a core dataset of 3020 proteins and a publicly-available database. Proteomics 5:3226-3245.

95.Kurulugama, R.T., S.J. Valentine, R.A. Sowell, and D.E. Clemmer. 2008. Development of a high-throughput IMS-IMS-MS approach for analyzing mixtures of biomolecules. J. Proteomics 71:318-331.

Received 9 February 2009; accepted 4 March 2009.

Address correspondence to Bill Brizzard, Indiana University Research and Technology Corporation, 501 North Morton Street, Suite 204, Bloomington, IN, 47401, USA. email: bbrizzar@iu.edu 